\title{
Genotype-by-environment interaction and yield stability analysis in sorghum (Sorghum bicolor (L.) Moench) genotypes in North Shewa, Ethiopia
}

\author{
Sintayehu ADMAS ${ }^{1}$ and Kassahun TESFAYE ${ }^{2}$ \\ ${ }^{1}$ Ethiopian Biodiversity Institute, P.O. Box 30726, Addis Ababa, Ethiopia, \\ e-mail: sintayehu@ibc.gov.et \\ ${ }^{2}$ Addis Ababa University, P.O. Box 3285, Addis Ababa, Ethiopia, \\ e-mail: kassahun.tesfaye@aau.edu.et
}

\begin{abstract}
A multi-environment sorghum variety trial comprised of nine genotypes along with one standard check, "yeju", was carried out in the main cropping seasons of the period of 2006-2008. The objective of this research was to identify a stable and betteryielding sorghum variety under the conditions of the sorghum-growing area of North Shewa, Ethiopia. The experiment was arranged in randomized complete block design replicated three times within an experiment. AMMI analysis based on grain yield data revealed that genotypes ICSV 1112BF, 82 LPYT-2 \# 5x81ESIP 46, and PGRC/E \#222880 were superior to the standard check both in grain yield and stability, and hence these genotypes have been verified, and the genotype PGRC/E \#222880 has been registered by the national variety-releasing technical and standing committee by the given name "Chare" for commercial production for the North Shewa sorghum-growing areas.
\end{abstract}

Keywords: MMI, PCA1, variety development, wide adaptation

\section{Introduction}

Sorghum (sorghum bicolor (L.) Moench) is an important cereal crop of the semi-arid areas of the tropics and sub-tropics, including Ethiopia, after wheat, rice, and maize with over $80 \%$ of the crop in Africa and Asia. It is also the major cereal crop in Ethiopia following tef and maize in terms of area coverage [1]. Sorghum has been produced in more than five million households and its annual production is estimated to be 4 million metric tons from nearly 2 million hectares of land [1]. Sorghum covers a significant amount of cultivated land following tef in the lowland areas of North Shewa Zone of Amhara region. As it is native to Ethiopia, it has remarkable genetic diversity as evidenced by many landrace collections 
made in the country. It is well adapted to a wide range of environmental conditions in semi-arid Africa [2]. It is mainly produced in medium and lowlands of Ethiopia. It withstands hot and dry condition better than most cultivated crops in Ethiopia. Sorghum is grown for its grain used as food and local beverages; nowadays, its stalk has also become an alternate source of animal feed as well as fuel. However, the average yield trends are downwards.

In North Shewa, sorghum is the primary crop cultivated especially in the lowlands. It contributes to food security at household level. Notwithstanding the immense potential uses of sorghum in Ethiopia in general and in North Shewa in particular, several biotic and abiotic factors inescapably induce an absolute reduction of grain yield of sorghum, and consequently the gap between demand and supply is still wide. In recent years, in North Shewa, despite a preferable, good yielding, late-maturing local landraces producing sorghum has become a risky business. Presumably coupled with climatic changes, the rainfall becomes unpredictable. Rainfalls occur infrequently and start late. In addition to this, anthracnose disease infestation is a major yield-reducing factor of sorghum production in North Shewa. Thus, it is indispensable to look for relatively early maturing, drought resistance, moderate to high anthracnose-disease resistance, and better adapting varieties which will give a reasonable yield relative to the pattern and distribution of rainfall. Therefore, sorghum variety trial was started with the objective of developing a stable, early maturing, anthracnose-disease resistant, and acceptable yielding ability sorghum variety under conditions existing in the North Shewa sorghum-growing area.

\section{Materials and methods}

\subsection{Experimental design}

Eight promising sorghum genotypes along with the standard check "yeju" were arranged in randomized block design with three replications. Local checks of the respective locality were included in the experiment; however, due to terminal drought stress, the local checks did not produce seed, and finally the local checks were excluded from the analysis. The experiment was conducted in the lowland area of Shewa Robit and Alem Ketema for three years - 2006-2008 (Table 1). The experimental plots were fertilized with $100 \mathrm{~kg} / \mathrm{ha}$ urea and $50 \mathrm{~kg} / \mathrm{ha}$ DAP. All DAP and half of the urea were applied during planting, while the other half of UREA was added when the crop reached knee height. Seeds were drilled at the rate of 20 $\mathrm{kg} / \mathrm{ha}$ in $75-\mathrm{cm}$ spaced six rows, each of them being 5-m long. The agronomic practices were applied uniformly to all experimental plots as per the recommendation for sorghum. Data on days to heading, days to maturity, plant height, disease score, grain yield, and thousand-grain weight were recorded on plot basis. 
Table 1. Description of the test environments of the field experiment

\begin{tabular}{|l|l|l|l|l|l|}
\hline No & \multicolumn{1}{|c|}{ Locations } & \multicolumn{1}{|c|}{$\begin{array}{c}\text { Altitude } \\
(\mathbf{m})\end{array}$} & \multicolumn{1}{|c|}{ Latitude } & \multicolumn{1}{|c|}{ Longitude } & Soil type \\
\hline 1 & Shewa Robit & 1,680 & $12^{\circ} 01^{\prime} 0.011^{\prime \prime N}$ & $39^{\circ} 37^{\prime} 59.99^{\prime \prime} \mathrm{E}$ & $\begin{array}{l}\text { Vertisols to } \\
\text { Light soil }\end{array}$ \\
\hline 2 & Aleme Ketema & 1,450 & $10^{\circ} 3^{\prime} 24.63^{\prime \prime N}$ & $38^{\circ} 59^{\prime} 43.79^{\prime \prime} \mathrm{E}$ & $\begin{array}{l}\text { Vertisols to } \\
\text { Light soil }\end{array}$ \\
\hline
\end{tabular}

2.2 Statistical analysis

\subsubsection{Combined Analysis of Variance}

Combined analysis of variance was performed using the procedure outlined by Steel and Torrie [3] for each measured parameter using IRRISTAT for Windows ver. 5.0. [4]. The following model for the combined ANOVA was used: $Y_{i j k m}=\mu+b_{i}+l_{j}+y_{k}+(l y)_{j k}+b(l y)_{j k}+t_{m}+(t l)_{j m}+(t y)_{k m}+(l y t)_{j k m}+e_{i j k}$, where $Y_{i j k m}=$ the yield observation from the $t^{\text {th }}$ block, the $j^{\text {th }}$ location, $k^{\text {th }}$ year of $m^{\text {th }}$ genotype $\mu$ is the experimental grand mean, $b_{i}$ the random block effect; $l_{j}$ is the random location effect, $y_{k}$ the random year effect, $t_{m}$ is the fixed genotype effect, $(l y)_{j k}$ is the random location by year interaction, $(t l)_{j m}$ is the random genotypes by location interaction $(t y)_{\mathrm{km}}$ is the random genotypes by year interaction effect; $(l y t)_{j k m}$ is the random location, year and genotype interaction effect, and $e_{i j k}$ is the random experimental error.

\subsubsection{Stability analysis}

The GEI sum square was done using the Additive Main and Multiplicative Interaction /AMMI/ model, as described in Nachit et al., 1992 [5, 6]. The AMMI model takes the following equation:

$$
y_{g e}=\mu+\alpha_{g}+\beta_{e}+\sum \lambda_{n} \gamma_{g n} \delta_{e n}+\theta_{g e}+\varepsilon_{g e r},
$$

where $y_{g e}=$ is grain yield of variety $g$ in environment $(e), \mu$ is the grand mean, $\alpha_{g}=$ the variety mean deviations (the variety means minus the grand mean), $\beta_{e}=$ are the environment mean deviations (the environment mean minus the grand mean),

$\lambda n=$ the eigenvalue of $n^{\text {th }}$ principal components analysis (PCA) axis $n$,

$\gamma_{g n}=$ the variety eigenvector value for IPC axis $n$,

$\delta_{e n}=$ is the environment eigenvector value for IPC axis $n$,

$\varepsilon_{g e}=$ is the random error. 


\section{Results and discussion}

\subsection{Analysis of variance}

The results of the combined analysis of variance across locations and over years revealed that location, year, location by year, genotypes, location by genotypes, year by genotypes, and location by year by genotypes showed a significant effect, while rep and rep by location by year had no significant effect on grain yield (Table 2). This shows the existence of GEI that affects the performance grain yield of the genotypes across location. GEI is the critical factor that discourages breeder and geneticist since it complicates the plant variety development programme for most crops to produce a stable variety across different seasons. Genotypes' mean agronomic performance is indicated in Table 3.

The combined analysis of variance of three years' data of Shewa Robit and Alem Ketema indicates that the grain yield performances of promising genotypes are significantly affected by year, locations, and GEIs. And these data considered for this experiment deviate from the already accepted analysis of variance assumption that it is additive in nature. And the information that is drawn from this analysis may mislead our result conclusion. Therefore, selecting the best genotypes based on mean grain yield is not recommended for this experiment. Hence, it is mandatory to split the contribution of individual sorghum genotypes to create the total GEI effect. And similar research results have been reported for most crops under Ethiopian conditions as, for example, Muhe and Assefa (2011) for bread wheat [7], Gedif and Yigzaw (2014) for potato [8], Adugna et al. (2011) for finger millet [9]. This calls for the use of another model that fits the proper evaluation of the tested genotypes, and several methods are used to analyse GEI [10, 11, 12]. This is because Ethiopia has diverse environmental conditions in terms of altitude, soil type, and climate variabilities, and developing stable varieties with wider adaptability is a difficult task for the plant-breeding programme in Ethiopia.

The grain yield change that is observed among genotypes is due to GEI, and GEI effect has to be considered during analysis. Hence, this urges us to use a more reliable and accurate method of analysis to increase the success of developing a stable variety. Several methods have been developed to select genotypes with greater stability for different ranges of environments, which also helps to estimate their performance under similar scenarios $[10,11]$. Among these, the additive main effects and multiplicative interaction (AMMI) model is the choice of most breeders to analyse GEI [13]. 
Table 2. The combined analysis of variance of the genotypes tested at Shewa Robit and Alem Ketema, Ethiopia, in the 2006-2008 cropping seasons (three years)

\begin{tabular}{|c|l|c|l|l|l|l|}
\hline No & $\begin{array}{c}\text { Source of } \\
\text { variation }\end{array}$ & d.f. & $\begin{array}{c}\text { Sum of } \\
\text { squares }\end{array}$ & $\begin{array}{c}\text { Mean } \\
\text { squares }\end{array}$ & $\begin{array}{c}\text { F } \\
\text { Ratio }\end{array}$ & $\begin{array}{c}\text { Prob } \\
\text { at 1\% }\end{array}$ \\
\hline 1 & Rep & 2 & 814688 & 407344 & 0.64 & 0.537 \\
\hline 2 & Loc & 1 & 232539000 & 232539000 & 362.54 & 0.000 \\
\hline 3 & Year & 2 & 395924000 & 197962000 & 308.64 & 0.000 \\
\hline 4 & Year*Loc & 2 & 39052900 & 19526400 & 30.44 & 0.000 \\
\hline 5 & Year*Loc*Rep & 10 & 10601800 & 1060180 & 1.65 & 0.103 \\
\hline 6 & VC & 8 & 36267100 & 4533390 & 7.07 & 0.000 \\
\hline 7 & Loc*VC & 8 & 28258000 & 3532250 & 5.51 & 0.000 \\
\hline 8 & Year*VC & 16 & 27372700 & 1710790 & 2.67 & 0.002 \\
\hline 9 & Year*Loc*VC & 16 & 26850600 & 1678160 & 2.62 & 0.002 \\
\hline 10 & Residual & 96 & 61575300 & 641409 & - & - \\
\hline 11 & Total & 161 & 859256000 & 536990 & - & - \\
\hline
\end{tabular}

Table 3. The mean performance of sorghum genotypes at Shewa Robit and Alem Ketema, Ethiopia, for three consecutive years (2006-2008)

\begin{tabular}{|l|l|l|l|l|l|l|}
\hline Code & \multicolumn{1}{|c|}{ Variety } & DTH & DTM & PLH & TSW & $\begin{array}{c}\text { Grain } \\
\text { Yield } \\
\text { (Kg/Ha) }\end{array}$ \\
\hline V1 & ICSV 1112BF & 69.22 & 109.94 & 143.81 & 2.93 & 4331.09 \\
\hline V2 & 82 LPYT-2 \# 5x81ESIP 46 & 72.56 & 111.17 & 135.69 & 2.913 & 4288.99 \\
\hline V3 & IS -777 & 74.17 & 113.11 & 179.36 & 2.43 & 3545.67 \\
\hline V4 & Yeju (standarde ck ) & 70.11 & 107.44 & 174.10 & 3.69 & 3919.89 \\
\hline V5 & IS 776 & 75.78 & 130.50 & 201.38 & 2.99 & 3779.20 \\
\hline V6 & P- 898012 X 435124 & 75.00 & 113.22 & 165.69 & 2.70 & 4465.95 \\
\hline V7 & 148XE3541)-4-1XCS3541DRAIVE-5-4-2-1 & 70.89 & 110.39 & 216.73 & 2.90 & 3729.37 \\
\hline V8 & PGRC/E \#222880 & 70.50 & 112.50 & 184.20 & 3.43 & 4005.95 \\
\hline V9 & PGRC/E \#222878 & 75.44 & 114.94 & 203.50 & 2.34 & 2812.83 \\
\hline & Mean & $\mathbf{7 2 . 6 3}$ & $\mathbf{1 1 3 . 6 9}$ & $\mathbf{1 7 8 . 2 7}$ & $\mathbf{2 . 9 3}$ & $\mathbf{3 8 7 5 . 4 4}$ \\
\hline & SE(N= 18) & 0.60 & 5.65 & 6.19 & 0.06 & 188.77 \\
\hline & 5\%LSD 96DF & 1.67 & 15.86 & 17.39 & 0.16 & 529.86 \\
\hline
\end{tabular}

\subsection{AMMI analysis}

GEI is very essential to be considered in a variety development programme to increase the chances of getting a stable variety that can fit into different environments with comparably constant performance in grain yield and also help in identifying the genotype that performs best in a given locality, as GEI affects the performances of genotypes in different environments and seasons. Those genotype that are not affected by GEI will be adapted to a vast area of environment, while 
those genotypes that are highly affected by GEI will have inconstant performances in different environments. In most cases, in Ethiopia, it is very difficult to develop varieties with a wider adaptation range because of the diverse nature of the environments. Therefore, an area-specific variety development is required in Ethiopia.

GEI can be analysed using the AMMI method, which is the most commonly used one in stability and adaptability analyses since AMMI can check for model efficiency as well as data analysis accommodates the influences of each environment, which improves the accuracy of analysis results [13]. The model also describes the pattern of adaptation of genotypes in relation to the tested environments [14, 15].

\subsubsection{AMMI analysis of variance}

The AMMI analysis of variance applied on sorghum genotypes for grain yield in six environments revealed that $85 \%, 4.61 \%$, and $10.49 \%$ of the sum of squares were contributed by the environment, the genotype effects, and the GEI respectively (Table 4). It is clearly seen that the contribution of environmental variation to the sum of squares is considerable, and this means that the environment in which the experiment was undertaken is significantly different. In addition, the variation observed among genotypes for grain yield is largely due to environmental effects. Various authors also reported similar results for other sorghum genotypes tested at different locations and crop seasons $[16,17]$.

Table 4. Analysis of variance for grain yield of sorghum genotypes evaluated at Shewa Robit and Alem Ketema for three years (2006-2008), using the Additive Main effects and Multiplicative Interaction (AMMI) model, Ethiopia

\begin{tabular}{|l|c|l|l|c|c|c|c|}
\hline \multicolumn{1}{|c|}{ SOURCE } & D.F. & \multicolumn{1}{|c|}{ S.S. } & \multicolumn{1}{|c|}{ M.S. } & \multicolumn{1}{|c|}{ F } & $\begin{array}{c}\text { F- } \\
\text { prob }\end{array}$ & $\begin{array}{c}\text { \% } \\
\text { explained }\end{array}$ & $\begin{array}{c}\text { \% accu- } \\
\text { mulated }\end{array}$ \\
\hline Gentotypes & 8 & 12089000 & 1511130 & & 0.000 & 4.61 & \\
\hline Environments & 5 & 222505000 & 44501000 & & 0.000 & 85.00 & \\
\hline TreatmentXEnvironments & 40 & 27493800 & 687344.0 & & 0.000 & 10.49 & \\
\hline AMMI Compnent 1 & 12 & 20899700 & 1741640 & 7.395 & 0.000 & 76.02 & 76.02 \\
\hline AMMI Compnent 2 & 10 & 3373040 & 337304. & 1.885 & 0.116 & 12.27 & 88.29 \\
\hline AMMI Compnent 3 & 8 & 2198940 & 274867. & 2.689 & 0.073 & 8.00 & 96.29 \\
\hline AMMI Compnent 4 & 6 & 789085. & 131514. & 2.257 & 0.224 & 2.87 & 99.16 \\
\hline GXE Residual & 4 & 233032. & & & & & \\
\hline Total & 53 & 262088000 & & & & & \\
\hline
\end{tabular}




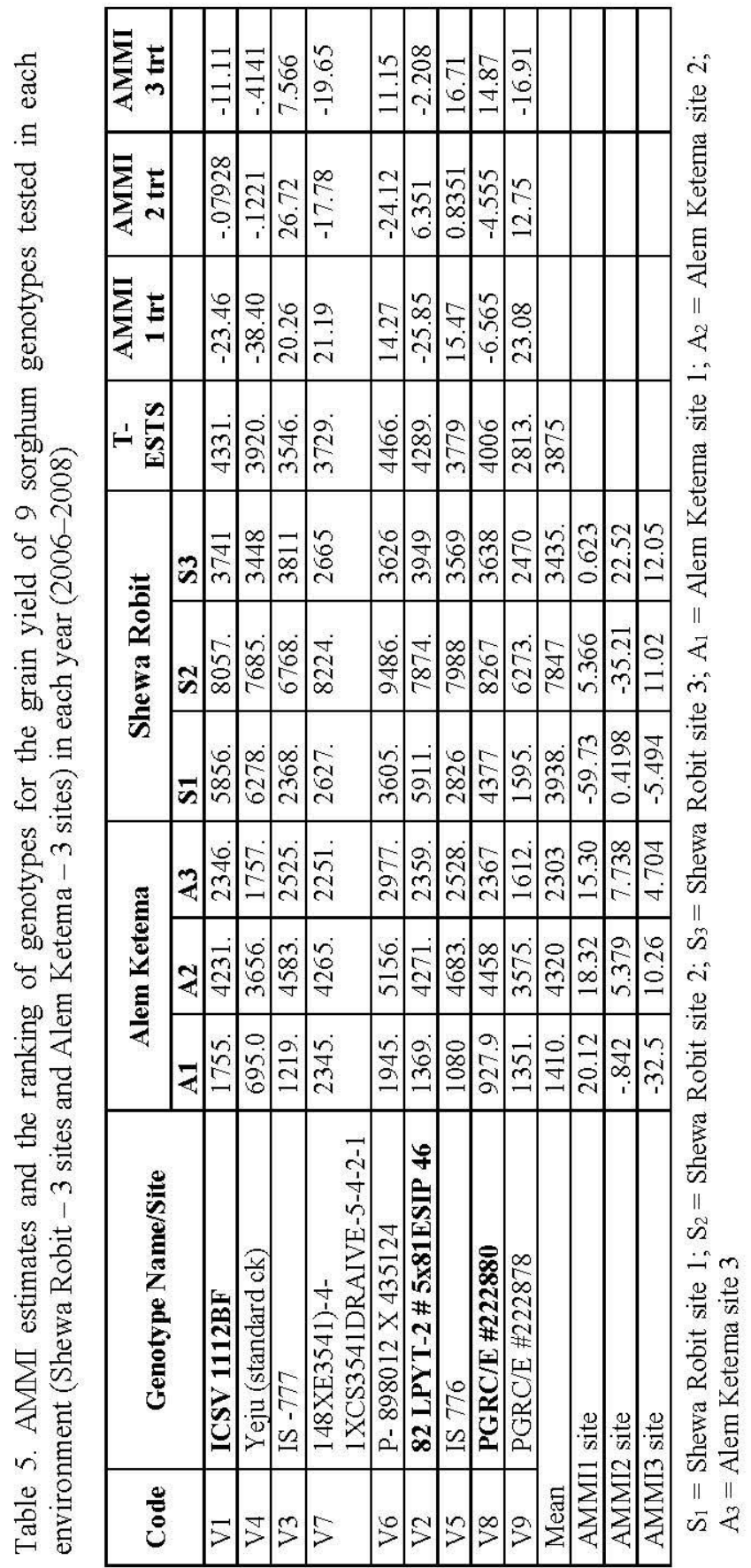


The AMMI analysis identified four principal component axes, and all contributed to $99.16 \%$ of the total variation observed among sorghum genotypes for grain yield due to GEI (Table 3). Of the four principal component axes, only AMMI Component 1 was significant at $\mathrm{P}<0.01 \%$. The first, second, third, and fourth interaction principal component (IPCA 1, IPCA 2, IPCA 3, and IPCA 4) axis explain $76.02 \%, 12.27 \%, 8.00 \%$, and $2.87 \%$ respectively. Here, the AMMI model adequately explains the total GEI broken down into different components. The GEI components' values in this experiment using AMMI model are comparable with the reports from Nida et al. [16] and Adugna [17].

\subsubsection{Biplot analysis}

The AMMI model was used to analyse Biplot graph (Figure 1) using individual environments and mean grain yield performances of sorghum genotypes in XY plan. $\mathrm{X}$-axis is designated for mean grain yield, while $\mathrm{Y}$-axis for IPCA 1 scores. As indicated in Figure 1, each environment and variety main effect was plotted along the abscissa against their respective IPCA1 score as ordinate. The red vertical line that crosses through the centre of the biplot is represented by the experimental grand mean of grain yield derived from all varieties and environments, while the red horizontal line shows the point where IPCA1 score $=0$. Those genotypes and environments that fall on the right side of the grand mean value of grain yield are rated as high-yielding genotypes and potential growing environments, and the remaining ones which fall on the left side of the grand mean are low-yielding genotypes and low-potential environments for sorghum production. Genotypes and environments located at the same side of the IPCA axis are interacting positively and produce desirable effects. Therefore, in this study, genotypes V1, V2, V4, V6, and V8 gave grain yield above the mean and are considered high-yielding genotypes, while V3, V5, V7, and V9 gave below the mean and are considered as low-yielding genotypes. Environments A2, S1, and S2 are high-potential environments, while A1, A2, and S3 are poor-yielding environments. Genotype V6 is best suited to environments S2 and A2, genotypes $\mathrm{V} 3, \mathrm{~V} 5, \mathrm{~V} 7$, and V9 to environments A1, A3, and S3, genotypes V1, V2, V4, and $\mathrm{V} 8$ to environment S1. AMMI adjusted and re-ranked the grain yield of each genotype by their respective IPCA axis score and environmental IPCA axis scores and thereby brought about a significant change in the ranks of genotypes when we compare them with the mean from combined analysis.

Genotypes and environmental contribution to the GEI were measured based on the magnitude of the corresponding IPCA 1 score, which is measured as the perpendicular distance from the benchmark, IPCA $1=0$. Generally, the more genotypes or environments deviate from the IPCA $1=$ axis, the more they would contribute to the GEI variances and the more unstable they would be. Genotypes 
and environments at the extreme top or bottom edge of the biplot-Figure 1 - are known to contribute more than their counterparts located closer to the IPCA1 axis $=\mathrm{O}$ [18]. Accordingly, genotypes V5, V6, and V8 had a very low contribution to the total GEI sum square, whereas their counterparts, V2, V3, V4, V7, and 'V9', highly contributed to the GEI sum square, suggesting that they are highly interactive with growing environments.

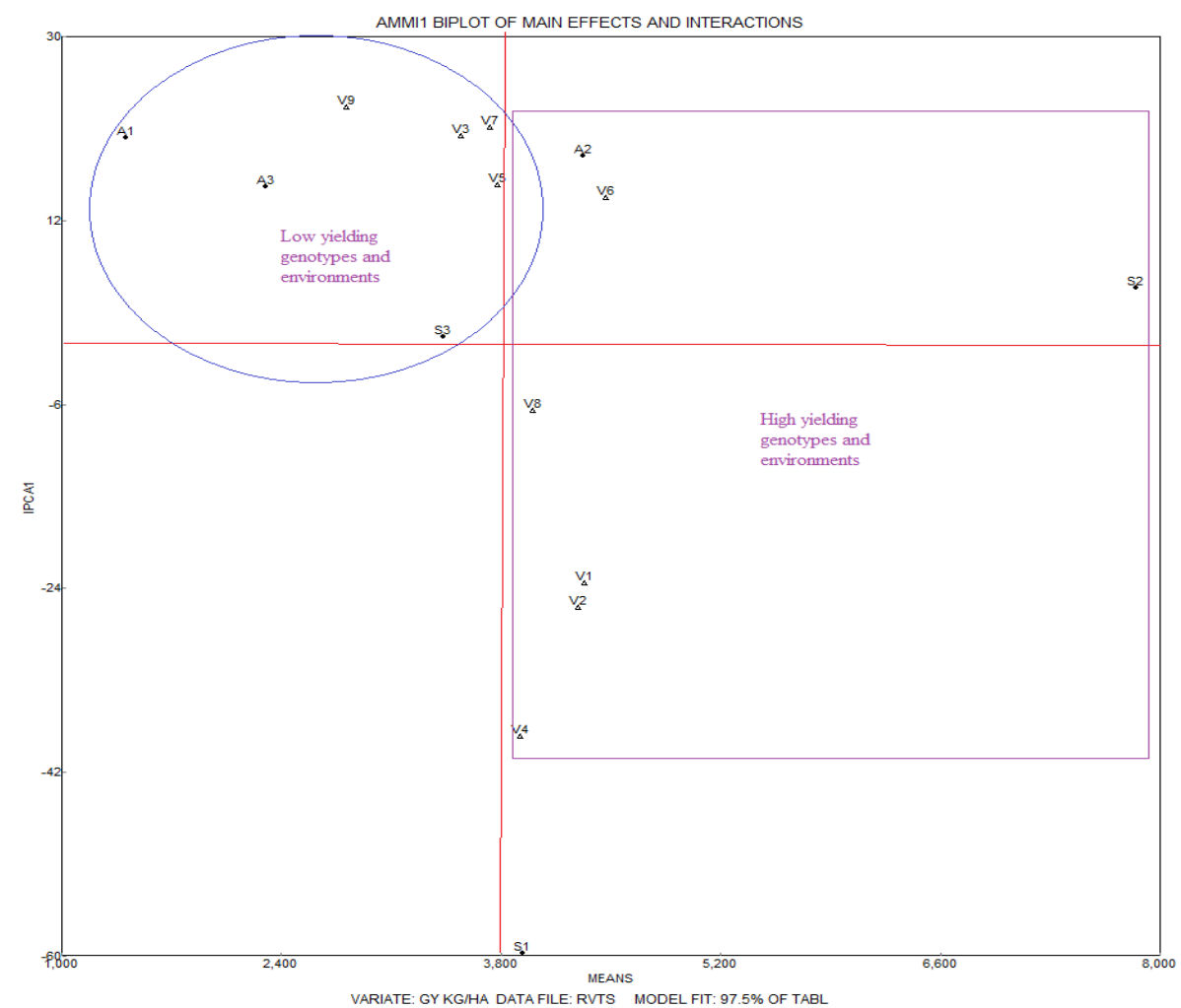

Figure 1. AMMI1 biplot for additive effects vs IPCA1 in nine sorghum genotypes evaluated for seed yield at two locations of North Shewa, Ethiopia during 2006-2008 $\mathrm{S}_{1}=$ Shewarobit site 1; $\mathrm{S}_{2}=$ Shewarobit site 2; $\mathrm{S}_{3}=$ Shewarobit site 3; $\mathrm{A}_{1}=$ Alem Ketema $1 \mathrm{~A}_{2}=$ Alem Ketema site $2 \mathrm{~A}_{3}=$ Alem Ketema site 3; V1-V9 = genotype 1 to genotype 9

AMMI2 biplot analysis using IPCA2 and IPCA1 is indicated in Figure 2. De Oliveira et al. (2014) pointed out that the stability information that is drawn using AMMI2 biplot is more precise than AMMI1 biplot because AMMI2 model contains information from IPCA1 and IPCA2 [19]. In AMMI2 model, those 
genotypes which are close to the nearby environment will perform better in that specific environments than those genotype which are far away [19]. AMMI2 also quantifies stability using AMMI stability value (ASV).

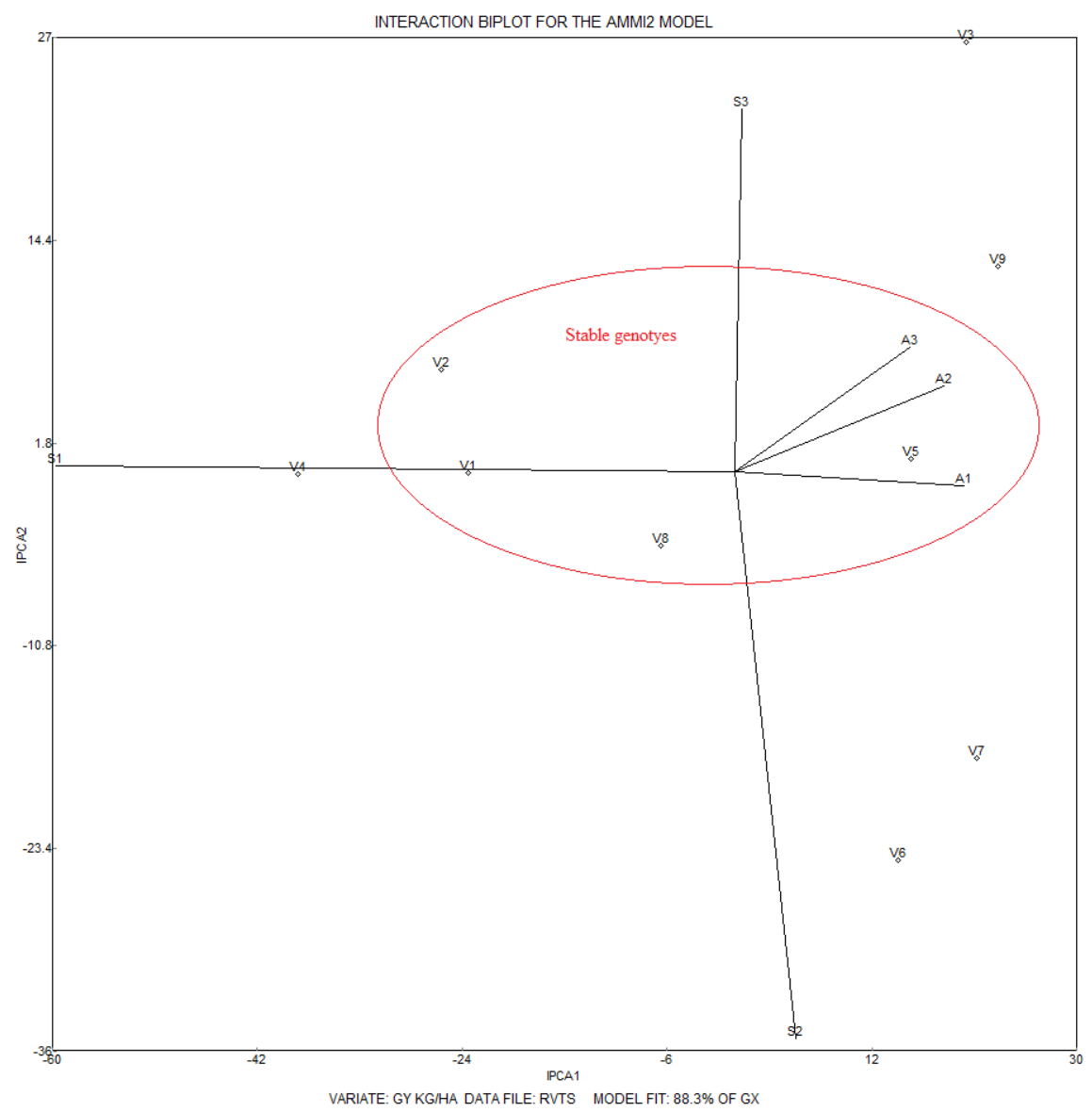

Figure 2. AMMI2 biplot showing the two main axes of interaction (IPCA2 vs IPCA1) in nine sorghum genotypes evaluated for seed yield at two locations of North Shewa, Ethiopia during 2006-2008

$\mathrm{S}_{1}=$ Shewarobit site $1 ; \mathrm{S}_{2}=$ Shewarobit site $2 ; \mathrm{S}_{3}=$ Shewarobit site $3 ; \mathrm{A}_{1}=$ Alem Ketema 1 $\mathrm{A}_{2}=$ Alem Ketema site $2 \mathrm{~A}_{3}=$ Alem Ketema site 3; V1-V9=genotype 1 to genotype 9

ASV is the distance from the vertex of IPCA 1 and IPCA 2 to the genotypes or environments that fall in the AMMI2 biplot graph. This value is finally used to measure the grain yield stability of the genotype and cluster the genotypes and 
environments into different groups [20,21]. Genotypes or environments which are very close to the vertex are more stable than those genotypes or environments away from the vertex. In other words, genotypes or environments that have less value of ASV score tend to be more stable than those genotypes or environments having high ASV score. Therefore, environment A1 (Alem Ketema Site 1), A2 (Alem Ketema Site 2), and A3 (Alem Ketema Site 2) are more stable environments for sorghum production compared to S1 (Shewa Robit Site 1), S2 (Shewa Robit Site 2), and S3 (Shewa Robit Site 3). With regard to genotypes, genotypes V1, V2, V5, and V8 are more stable than the remaining genotypes; however, only genotypes V1 (ICSV 1112BF), V2 (82 LPYT-2 \# 5x81ESIP 46), and V8 (PGRC/E \#222880) are high-yielding ones (Figure 2). Then these genotypes were promoted for verification trial in 2009, and only genotype V8 (PGRC/E \#222880) was released by the national releasing committee, while the remaining two genotypes were rejected by the committee because farmers had disliked these genotypes. Finally, genotype V8 (PGRC/E \#222880) was registered by the given name "Chare" in 2009. Similarly improved varieties have been released using AMMI model in Ethiopia as, for example, finger millet [9] and bread wheat [7].

\section{Conclusions}

GEI is an important factor for developing a stable variety that fits wider adaptation areas. In Ethiopia, GEI is vital for plant-breeding programmes where there is a diverse natural environmental, climatic and soil variability. In this study, nine promising genotypes were tested at Shewa Robit and Alem Ketema for three years to examine the grain yield performance and stability status of the genotypes and select the best genotype for variety release for commercial use. The combined analysis of variance is not appropriate for selecting a promising genotype to handle GEI. So, AMMI model is the most widely used technique to handle GEIs. In this experiment, AMMI Stability Value (ASV) and Biplot Analysis are effective and most appropriate tools to describe and identify stable and superior genotypes for most crops. In this experiment based on the AMMI analysis parameters, genotypes V1 (ICSV 1112BF), V2 (82 LPYT-2 \# 5x81ESIP 46), and V8 (PGRC/E \#222880) gave comparable yield in all the six different environments in North Shewa. And this genotype can be considered as stable in terms of grain yield performances and as well-adapted to the tested environments. However, genotype V8 (PGRC/E \#222880) is therefore released to be used in North Shewa sorghum-growing areas and also for similar agroecological regions in Ethiopia. 


\section{Acknowledgments}

The authors would like to express their thanks to D/Brihan Agricultural Research Center for their support as well as Neway Tefera and Adugna Worku for their assistance for data collection and recording.

\section{References}

[1] CSA (Central Statistical Agency), Federal Democratic Republic of Ethiopia. (2015/16), Agricultural sample survey report on area and production of crops, volume II. Addis Ababa, Ethiopia.

[2] Dewar, J. (2003), Influence of malting on sorghum grain protein. CSIR. Environmental. Longman scientific and technical Co. Ltd. 200-209.

[3] Steel, R. G. D., Torie, J. H. (1980), Principles and procedure of statistics. A biometrical approach. N. Y.: McGraw-Hill, 195-233.

[4] IRRI 2005. IRRISTAT for Windows ver. 5.0. Philippines: Metro Manila.

[5] Finlay, K. W., Wilkinson, G. N. (1963), The analysis of adaptation in plant breeding programmes. Australian Journal of Agricultural Research 14, 742-754.

[6] Nachit, M. M., Sorrels, M. E., Zobel, R. W., Gauch, H. G., Fisher, R. A., Coffman, W. R. (1992-II), Association of environmental variables with sites' mean grain yield and components of GEI in durum wheat. J. Genet. Breed. 46, 369-372.

[7] Muhe, K., Assefa, A. (2011), Genotypes X environment interaction in bread wheat (Triticum aestivum L.) cultivar development in Ethiopia. Int. Res. J. Plant Sci. 2(10), 317-322. ISSN: 2141-5447.

[8] Gedif, M., Yigzaw, D. (2014), GEI analysis for tuber yield of potato (Solanum tuberosum L.) using a GGE biplot method in Amhara Region, Ethiopia. Agricultural Sciences 5, 239-249. http://dx.doi.org/10.4236/as.2014.54027.

[9] Adugna, A., Tesso, T. Degu, E., Tadesse, T., Merga, F., Legesse, W. Tirfessa, A., Kidane, H. Wole, A., Daba, C. (2011), Genotype-by-environment interaction and yield stability analysis in finger millet (Elucine coracana L. Gaertn) in Ethiopia. American Journal of Plant Sciences 2, 408-415. doi:10.4236/ajps.2011.23046.

[10] Kang, M. S., Gauch, H. G. (eds). (1996), Cultivar-by-environment interaction. CRC Press, Boca Raton, FL.

[11] Piepho, H. P. (1998), Methods for comparing the yield stability of cropping systems - a rev. $J$. Agron. Crop Sci. 180, 193-213.

[12] Yan, W., Hant, L. A., Qinglai, S., Szalvincs, Z. (2000), Cultivar evaluation and megaenvironment investigation based on the GGE Biplot. Crop Science 40, 597-605. http://dx.doi.org/10.2135/ cropsci2000.403597x.

[13] Gauch, H. G. (1988), Model selection and validation for yield trials with interaction. Biometrics 44: 705-715.

[14] Zobel, R. W., Wright, M. J., Gauch, H. G. (1988), Statistical analysis of a yield trial. Agronomy Journal 80, 388-393.

[15] Crossa, J., Gauch, H. G., Zobel, R. W. (1990), Additive main effect and multiplicative interaction analysis of two international maize cultivar trials. Crop Science 30, 493-500.

[16] Nida, H., Seyoum, A., Gebreyohannes, A. (2016), Evaluation of yield performance of intermediate altitude sorghum (Sorghum bicolor (L.) Moench) genotypes using Genotype x Environment Interaction Analysis and GGE Biplot in Ethiopia. International Journal of Trend in Research and Development 3(2), 27-35. ISSN: 2394-9333. 
[17] Adugna, A. (2008), Assessment of yield stability in sorghum using univariate and multivariate statistical approaches. Hereditas 145, 28-37.

[18] Duarte, J. B., Vencovsky, R. (1999), Genotype $\times$ environment interaction: an introduction to AMMI analysis [Interação genótipos $\times$ ambientes: uma introdução à análise AMMI]. Sociedade Brasileira de Genética, Ribeirão Preto, SP, Brazil.

[19] de Oliveira, E. J., de Freitas, J. P. X., de Jesus, O. N. (2014), AMMI analysis of the adaptability and yield stability of yellow passion fruit varieties. Sci. Agric. 71(2), 139-145.

[20] Verma, R. P. S., Kharab, A. S., Singh, J., Kumar, V., Sharma, I., Verma, A. (2016), AMMI model to analyse GxE for dual purpose barley in multi-environment trials. Agric. Sci. Digest. 36(1), 9-16.

[21] Purchase, J. L., Hatting, H., Vandeventer, C. S. (2000), Genotype $\times$ environment interaction of winter wheat (Triticum aestivum L.) in South Africa. II. Stability analysis of yield performance. South African Journal of Plant and Soil 17, 101-107. 